\title{
Ethics and Sustainability: Guest or Guide? On Sustainability as a Moral Ideal
}

\author{
Franck L. B. Meijboom • Frans W. A. Brom
}

Accepted: 10 June 2011

(C) The Author(s) 2011. This article is published with open access at Springerlink.com

\section{Sustainability Discussion: Ethics as a Guest}

In September 2007 the European Society for Agricultural and Food Ethics (EurSafe) organized its seventh conference, entitled "Sustainable Food Production and Ethics". The importance of discussing issues of sustainability with respect to food production is almost evident. Sustainability is on the public agenda and will not easily disappear. It has become an issue widely debated in many countries, and many organizations such as the FAO and retail multinationals have their own sustainable development department. From this perspective, it seems an apt choice to organize a conference on sustainable food production from the perspective of ethics.

Nonetheless, one can wonder what role ethics has to play in the sustainability discussion and to what extent ethics has real added value. Discussions on sustainability often appear in terms of technical debates on, for instance life cycle analyses, supply chain management or scenarios on climate change.

On the one hand, ethics clearly plays a role in these debates, because such complex assessments or scenarios include a number of value assumptions and use concepts such as risk, safety, health, and welfare that all ask for more than mere technical competence. At this stage problems of, for instance, precautionary reasoning pops up. It illustrates that sustainability confronts us with the fundamental question how it is possible to ascribe responsibilities to actions for which we are not able to oversee the consequences. To answer such questions, fundamental ethical reflection is needed next to science.

On the other hand, one can argue that in spite of the importance of ethical reflection on these value-laden concepts and the problems of uncertainty and precaution, these activities are not specific for the sustainability discussion.

F. L. B. Meijboom $(\bowtie) \cdot$ F. W. A. Brom

Ethics Institute, Utrecht University, Janskerkhof 13a, 3512 BL Utrecht, The Netherlands e-mail: f.l.b.meijboom@uu.nl 
Explicating the implicit assumptions that underlie the definition of a situation as dangerous or uncertain, or to discuss the moral importance of health and safety are well-known from other practices, such as risk assessment and public health prevention. From this perspective sustainability is mainly a debate among natural scientists where ethics is welcomed from time to time as a guest rather than as a guide.

In this introduction and with this special issue we aim to show that ethics can be more than a mere guest in the sustainability discussion if we start in the notion of sustainability as a moral ideal.

\section{Sustainability as a Moral Ideal}

With van der Burg, we define moral ideals as "values that are usually implicit or latent in the law or the public or moral culture of a society or group, which usually cannot be fully realized and which partly transcend contingent, historical formulations and implementations in terms of rules and principles " (van der Burg 2004 , p. 29). From this perspective, moral ideals are in principle dynamic and open, but they are not empty. Even stronger, moral ideals are essential to understand and guide normative practices, because they structure the deliberation about the desirable future states of affairs that these practices strive for (Brom 1998; van der Burg 1997).

The notion of sustainability as a moral ideal is relevant to understand the possible roles ethics can play in the discussion on the future of agriculture for at least three reasons. First, it explicates the normative component of sustainability, especially when sustainability is discussed in mainly technical and factual terms. Explicating the moral ideals that are implicit in these apparently technical discussions helps to understand the normative component in these discussions. Ideals highlight the future states of affairs that are worthwhile striving for. Sustainability seen as an ideal does not directly lead to a discussion in terms of moral duties or principles. The role of ethics, however, is not restricted to the level of principles and duties, but also includes reflection on which states of affairs are worthwhile striving for and for what reasons they are that worthwhile. Sustainability as an ideal highlights the arguments that give sense to our striving for a sustainable agriculture.

Second, sustainability as a moral ideal can help to deal with the problem of the lack of a univocal definition for sustainability. In spite of a number of reports on sustainability, such as the Brundlandt Report (1987), there is still an ongoing discussion on the concept of sustainability. A focus on the notion of sustainability as an ideal will not solve the conceptual problems, but it will help to distinguish between specific conceptions that are directly relevant for practical orientation and that are often more consensual on the one hand and the more future oriented aspects that transcend the attempts to formulate specific conceptions (cf. van der Burg 2003, p. 26). In this way the ideal can highlight specific unsustainable practices that need more technical solution-focused discussions and discussions on the morally preferred direction of sustainable development. 
Finally, sustainability as a moral ideal helps to open up sustainability for fundamental critical reflection without hampering it as guide for practice. As said above, ideals are open but not empty. They are more than mere utopian ideas, because they can serve as a source of critical reflection. Thus specific solutions to an ethical question or practical principles guiding these solutions can be questioned and discussed from the perspective of the underlying moral ideal (cf. Brom 1998) In this sense moral ideals can be both action guiding and source for critical reflection, i.e., the notion of sustainability as an ideal combines both the idea of sustainability as a direction and as a practical concept that support transformation into that direction.

Nonetheless, the notion of moral ideals has limits. As we have argued elsewhere ideals cannot be direct morally binding (Brom et al. 2007). They rather function as a perspective, a compass that gives direction to one's deliberation. However, if one recognizes an ideal, it is clear that one wants to live up to it. And that they can come with obligations and can be morally action guiding.

If these aspects are taken seriously ethics can be more than a guest in the sustainability debate. It can contribute to discussions on the content of sustainability as a compass that give directions to human action. It can provide input to the evaluation to the variety of proposals to define the direction of sustainable development, but also contribute to the discussion on moral motivation, moral beliefs and the quality of moral arguments with respect to sustainability. Especially the latter three are central in the papers of this special issue.

\section{Sustainable Food Production: Motives, Practices and Ethical Side Constraints}

The notion of sustainability as a moral ideal does not only help to understand a number of issues. It also raises a number of questions. One of the first is on moral motivation. How is the ideal linked to actual decisions and behavior? The articles by Anthony and Kjærnes deal with this question.

Raymond Anthony's article on building a sustainable future for animal agriculture starts in the claim that agricultural technologies are non-neutral, raise ethical challenges, and-most important for the article-reflect the shape of our moral character. For a sustainable agriculture and food production, Anthony argues that we should use another paradigm for agriculture than the human-centricism that we used for the last decades. To strive for sustainability an environmental virtue ethic of care (EVEC) is needed. This type of ethic is presented to provide tools that enable us to critically reflect on the role of technology and help to understand and shape the moral attitude that is needed for the sustainability of our food production systems in the future.

Sustainability and the lack of consistency between people's engagement in ethical issues and their food choices is the point of departure for the paper by Unni Kjærnes. She argues that the dominant focus on the individual choice at the point of purchase is problematic if one wants understand the social and ethical issues related to food production and consumption. To understand 'consumer choice' a shift of focus is needed from the individual choice to a relational perspective. In this view 
consumer choice is understood as a political ideology addressing a particular way in which everyday practices can be directed $\mathrm{n}$ order to solve social problems.

The above-mentioned contributions to the discussion on moral motivation in the case of sustainable food production and consumption directly lead to a second level of questions. These questions are related to the empirical data on moral values and beliefs of the stakeholders in the agri-food sector and what these beliefs and values imply in practice.

The paper by Clemens Driessen focuses on the role farmers play in the public debate on the future of food. The article starts in the broad range of ethical issues that has emerged in livestock agriculture. Driessen claims that sustainability in this sector requires that the ethical concerns with respect to animal and environment need to be addressed as interlinked themes. Moreover, is asks for an approach that includes the whole spectrum of involved stakeholders. With respect to the latter point it is, however, striking that the views of farmers in the debate on sustainability have been largely absent or presented as only of marginal relevance. By discussing three approaches that aim to deal with the plurality of concerns, Driessen shows how the moral experience of farmers can be elaborated in order to strengthen their role in societal debates on improving the sustainability of livestock farming.

Sustainability as a moral ideal also has implications on a political and policy level. Tom MacMillan and Elizabeth Dowler focus their paper on this area by elaborating on the UK situation as an example. They show how the exclusively liberal and free-trade character of the food and agricultural policies changed at the turn of the twenty first century to include ecological sustainability and 'food security'. They analyze the implications of the shift in policy discourse for social justice in and through the food system.

Based on a broad range of empirical data and a focus on three initiatives of sustainability in the agri-food sector, Dirk Roep and Johannes Wiskerke propose a conceptual framework that can help policymakers that want to support the development of sustainable food supply chains. The framework starts in the assumption that the process of increasing sustainability in the agri-food sector is based on strategic choices with respect to three elements: governance, embedding and marketing and in the coordination of these three dimensions that are inextricably interrelated. The use of the framework is not limited to governance advice only. It also can be used as an analytical tool for studying food supply chain dynamics and as a reflexive tool for practitioners to help them to position themselves, develop a clear strategy. The paper elaborate on the latter use of the framework in order to get grip on the complexity of transformation processes towards sustainable food supply chains.

The latter paper already touches on a third range of questions. Sustainability as a moral ideal asks for the formulation of specific criteria and institutions that prevent that striving for this ideal frustrate the protection of other moral values such as autonomy and justice. Kristian Høyer Toft deals with the question of global justice in the context of genetically modified crops and food. He shows that the opposing views on how GMO's may contribute to alleviate global hunger and malnutrition raise questions of global justice next to questions of risk and benefit. Toft claims that these questions of justice are mainly on an institutional level. Stable and 
efficient institutions are required in order to provide the benefits from the technology, but the question is to which extent (existing) international institutions of GMO's are able to deal to include issues of global justice. He concludes that the credibility of the claim that GMOs are needed to feed the world depends on how justice is addressed and he proposes a conceptual framework of global justice theory, in particular the 'global basic structure' argument advanced by cosmopolitans for further elaboration.

Open Access This article is distributed under the terms of the Creative Commons Attribution Noncommercial License which permits any noncommercial use, distribution, and reproduction in any medium, provided the original author(s) and source are credited.

\section{References}

Brom, F. W. A. (1998). Developing public morality: Between practical agreement and intersubjective reflective equilibrium. In W. van der Burg \& T. van Willigenburg (Ed.), Reflective Equilibrium (pp. 191-202). Kluwer.

Brom, F. W. A., Visak, T., \& Meijboom, F. L. B. (2007). Food, citizens, and market, the quest for responsible consuming. In L. Frewer \& H. van Trijp (Eds.), Understanding consumers of food products (pp. 610-623). Cambridge: Woodhead.

Brundlandt, H. (1987). Our common future. Oxford: Oxford University Press.

van der Burg, W. (1997). The importance of ideals. Journal of Value Inquiry, 31, 23-37.

van der Burg, W. (2003). Dynamic ethics. Journal of Value Inquiry, 37, 12-34.

van der Burg, W. (2004). The role of ideals in legal dynamics. In Arend. Soeteman (Eds.), Pluralism and Law, Proceedings of the 20th IVR World Congress, Archiv für Rechts- und Sozialphilosophie Beiheft 91 (pp. 28-33). Stuttgart: Franz Steiner.

van der Burg, W., \& Taekema, S. (2004). Motivation by ideal. in discussion with J. David Velleman. Philosophical Explorations, 7(1), 91-98. 